\title{
Translating the Self: Ariel Dorfman's Bilingual Journey
}

To some extent, one has to rewrite the past in order to understand it (Hoffman, 1991a: 242).

To mouth foreign terms without incorporating their meanings is to risk becoming bowdlerised. A true translation proceeds by the motions of understanding and sympathy; it happens by slow increments, sentence by sentence, phrase by phrase (Hoffman, 1991b: 211).

Multivalence is no more than the condition of a contemporary awareness, and no more than the contemporary world demands (Hoffman, 1991c: 274).

In Making Signs and Making Subjects: The English Curriculum and Social Futures, Gunther Kress sets out a justification for a broad, rather than narrow, view of text when he writes: 'A text, any text, is a microcosm of the social world in which it is made. It encapsulates in an irrefutable form a cultural truth about the individ$\mathrm{ual}$ /s who produced it - be it a film, a letter, any text written in a place of work, a newspaper editorial' (Kress, 1995: 24). He goes on to suggest that what is needed is 'an overarching textual theory which accommodates texts of all kinds, and does not separate the mundane from the aesthetic' (Kress, p. 28). Such a textual theory, he continues, must take account of the fact that text is 'the product of many voices' and comes from 'many places in society' (p. 30). It is 'an object with a multiple producership and a multiple readership' (ibid.). While it is doubtful that in writing these words, Kress was thinking specifically about notions of (cultural) translation and (social) transformation as articulated by post-colonialist theorists such as Homi Bhabha, the issues raised challenge a hierarchical view of text which would separate them according to strict notions of period, provenance and genre. Rather, Kress appears to see texts, whether they be culturally salient, aesthetically valued or mundane, as (interdependent) sites of social, cultural and linguistic production. By studying both individual texts and their relationship to other textual products, it is possible to come to understand the dynamics of (meaningful) representation.

This is the context in which I wish to place Ariel Dorfman's lucid memoir of life as a bilingual (Spanish and English) and bicultural (American and Latin American) writer of text. Heading South, Looking North relates Dorfman's experience of living in 'translated' worlds: America as seen first through the eyes of a young boy whose initial rejection of Spanish and adoption of English is troubled only by his growing recognition of his family's difference as Jews and Communist sympathisers in McCarthyite America. Their subsequent journey to Chile unsettles the young Dorfman for whom English and American culture have provided a kind of anchor in an otherwise changing and uncertain world. With time and the re-learning of Spanish, however, he begins to view Chile through Latin American, rather than American, eyes. Then, as a student of Latin American Studies at Berkeley, comes a renunciation of English and of American 
cultural domination and a desire to re-assert his identity in Spanish. Somewhat ironically, it is with the publication of a book denouncing Donald Duck that Dorfman is lent the status he has been seeking as a Chilean writer. Later, however, in the Argentinian embassy in Santiago de Chile, where as an ardent supporter of Allende he has been forced to seek refuge, he finally comes to recognise what history has declared for him - life as a bilingual. '[I]t is in that embassy', he writes, 'that I first explore the possibility of living in two languages, using each one for a different community. It is there that I set out on the road to this hybrid mongrel of language [my italics] who writes this so many years later' (Dorfman, 1998a: 269).

What this potted biography brings to the fore is Dorfman's discomfort growing up as a bilingual. It is not until his early 30 s that an accommodation is reached between his Spanish-language and his English-language self. The journey which he narrates towards acceptance of what he calls his 'schizophrenic, adulterous existence' (p. 132), an existence which he comes to celebrate rather than to denounce, is a long and arduous one in the course of which he develops an understanding of the 'complexity of cultural interchange' (p. 252). It is a journey which is both personal and political, incorporating a search for cultural identity and a place in the social world from which to speak and act in a meaningful way. Dorfman's personal odyssey is at the same time the story of Latin America 'as it searched for a language with which to express its hybridity' (p. 191). Dorfman refers to the attempts both by Europeans and by North Americans to 'translate' Latin America, that is to understand it and articulate it in their own terms. As a mestizo, 'part Yankie, part Chilean, a pinch of Jew' (p. 220), Dorfman begins to see the possibility of using his bicultural, binational status to mediate between two continents and to tell the story of Chile in a language 'without any need of

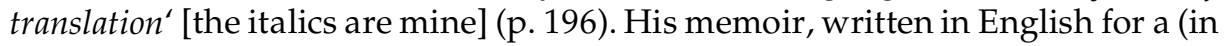
the first instance) largely North American audience, constitutes an attempt to come to terms both with his personal history and with that of the social and political world into which he was born, a world characterised by wars, revolutions and migrations. It is language in its relation to the construction of a cultural identity and of a social and political consciousness which is at the heart of Dorfman's narrative. Language is the medium which shapes and transforms his existence and which causes him pain and joy in equal measure. For it is through the languages available to Dorfman, namely Spanish and English, that he views and constructs the world. His experience of reality is mediated by the narratives historical, political and social - circulating around him and in relation to which he tries to locate and position himself.

That language is central to our perceptions of the world around us and to the ways in which we act upon it is one of the main themes of Heading South, Looking North. At the heart of the book is a concern with the possibilities and limitations of language and how use of a particular language in a historically and culturally-specific moment helps define our response to it. The politics of representation, that is the question of who gets to speak, which stories are told (and by whom), using which representational resources and for which purpose, is the central issue motivating Dorfman's narrative. His text constitutes a site for the expression of the value(s) of difference. For it is through writing, he comes to realise, that the tensions and contradictions of his (bilingual) existence can be 
mapped out and located. As he puts it: ' ...I found myself able to contact in my writing an ambiguity and a turbulence that had not till then been allowed expression' (p. 131). In representing his concerns in textual form, he is able to give voice to his different selves and in so doing 'translate' both for himself and for his reader the experience of 'being bilingual and binational at a time when everything demanded that we be univocal and immaculate' (p. 220).

And so Dorfman first rejects the idea of being what he calls 'a young man in between, no longer knowing his own name, adrift in a world torn by the two Americas inside and outside him' (p. 221). 'I was not even willing, at that point', he continues, 'to ask myself how the two languages differed, how each of them might complement or oppose the other, the subtle way in which English made me one kind of writer, one kind of person, and Spanish somebody else' (ibid.). Accordingly, he changes his name first from Vladimir (Vlady) to Edward and then from Edward to Ariel. This act of re-naming becomes a way of creating an identity with which Dorfman feels comfortable at particular moments in his life. The detested Vlady, given him at birth by his father in remembrance of Lenin, is given up for Edward, the very Englishness of the name aimed at separating him from his Latin American contemporaries. Yet while Edward as an index of Englishness permitted Dorfman to enjoy a measure of distinction at the British school, which he attended as an adolescent in Santiago de Chile, he begins to find it onerous as a university student in the Latin America of the 1960s and adopts instead his neglected middle name, Ariel, which he sees as a way of translating exactly his ambivalence with respect to his Spanish and English selves. 'For me, it became a way of defining my own growing disaffection with the land whose extreme materialism I had cherished and coveted, while at the same time subtly asserting my affiliation with the language that continued to be my constant companion and best friend, the English that had been elevated to its supreme pinnacle in the works of Shakespeare' (p. 160).

For Dorfman this process of re-naming is akin to a process of 'situating myself on the border between the continent of my birth and the world outside' (p. 161), a process of 'redefining my identity' (ibid.). Identity, then, is bound up in the process of naming and appropriating. 'I ate up that name and gave it the meaning that I so desired. I was Caliban the savage, cannibalising Ariel, the Hebrew Lion of God, for my own purposes' (p. 160). Language for Dorfman is not a (more or less) neutral means of representation but a culturally embedded system of signification which meets those it encounters carrying historical and political baggage. In order to create something new, the individual subject must ingest it, chew it, digest it, transform and transubstantiate it (see p. 161).

Almost as a survival tactic, Dorfman spends his early life suppressing one language in the interest of the other. Yet the Spanish which he had rejected as a young boy growing up in New York begins to re-assert itself, as does the English which he later vows to give up in order to attach himself more closely to Chile, a determination which he fails to achieve as English makes a comeback - the return of the repressed - even before he leaves Chile. Faced with the prospect of a long exile outside his country in a world where English has time and history on its side, Dorfman comes to acknowledge the possibility of co-existence for his two languages. He becomes what he calls a 'bigamist of language' (p. 270), sharing 
them and being shared by them as he heads North and looks 'to the South where I can no longer live ...' (ibid.).

Dorfman's life is circumscribed by a series of migrations, dislocations and relocations. Indeed his birth in Argentina was to parents who were in turn the children of Jewish émigrés from Eastern Europe. Dorfman's parents had conceived him in Spanish, a language which they had acquired rather than learnt at birth. Yiddish was the language with which his mother first came into contact, a language which she would later abandon for Spanish. By contrast, his father's adoption of Spanish was not at the cost of his native Russian, perhaps, Dorfman speculates, because his grandparents were polylingual and because his father had prior experience of Spanish, having emigrated not once but twice to Argentina. Dorfman contrasts his father's determined bilingualism with his mother's self-inflicted monolingualism, suggesting that his mother's abandonment of Yiddish had to do with the fact that Yiddish 'occupied no territory, possessed no name on the map of nations, had never been officially promoted by a state' (p. 21), unlike his father's native Russian which 'contained within its words the full force of its nationhood and literature and vast expanses' (ibid.). Past and present were, for Dorfman's father, able to co-exist, while for his mother the past became irrelevant to her present.

It is perhaps in this connection that Bhabha's notion of cultural translation can be understood. As he puts it: 'The transnational dimension of cultural transformation - migration, diaspora, displacement, relocation - makes the process of cultural translation a complex form of signification' (Bhabha, 1994: 172). In Ariel Dorfman's case, as in that of his parents, culture can be seen as 'a strategy of survival' (ibid.). That his own story is underwritten by the stories of those who came before him, is something of which Dorfman is consciously aware. Reflecting on his migratory existence from his adult perspective, he wonders whether such an experience might not have been fated. 'Maybe this was the fate of my family', he writes, 'maybe this was a curse I couldn't escape. Twice I had made the attempt to settle down, twice I had adopted a country and a culture and a language, and both times I had found myself fleeing, I had found myself homeless in spite of all my efforts, and now I was going to begin again, all over again. Except that this time I was no longer innocent' (Dorfman, 1998b: 275). What Dorfman takes away with him is a sense of exile, an exile contemplated through the dual lens of the myth of an eventual return to his place of origin and, simultaneously, an acknowledgement that his fate may be that of the wanderer, expelled from his native land and forced to find a future elsewhere.

And so Dorfman comes to the realisation that he is uniquely well placed by virtue of his bilingualism and biculturalism to tell not only his own story but also that of Chile and of those Chileans whose voices have never been heard. 'The story of their lives had never been told, the words had belonged to someone else ...Since their birth, those men and women had been told the limits they could not cross, the questions they could not ask' (pp. 243-4). Dorfman senses that he is ultimately in the privileged position of being able to give voice to a period of Chile's history from the perspective of an insider insofar as he participated in its political and cultural life at a moment of change and transformation; at the same time, however, as an adopted homeland and one which he was forced to abandon, he is also able to view Chile from the outside and to represent it at a distance, 
both temporal and geographic. He is thereby able to situate himself in relation to his Chilean past from the vantage point of his American present and to use his biculturality to express 'the mysterious center that unifies me in spite of language' [the italics are mine] (p. 221). His journey ends at the point where his two languages and their attendant cultures are able to co-exist. The youthful segregation and indeed suppression of one language by the other has given way to a recognition of the value of co-existence and complementarity. Indeed Dorfman's memoir embodies his attempts through revision and reinscription to 'translate' cultural and linguistic difference into a language which occupies a third space, located as it is at the meeting point of his Spanish and English selves.

Thus the English used by Dorfman is infused with the spirit of Latin America and of the Spanish which he came to master at the Grange, his English boarding school in Santiago de Chile, which he characterises as 'rememorating an old empire that no longer existed' (p. 113). The neologism, 'rememorating' is not simply a (mis)translation of the Spanish 'rememorar' but consciously combines the English notions of commemoration and remembrance in a term freshly coined for the occasion and available to Dorfman because of his bilingualism. His syntax and choice of vocabulary, therefore, can be seen to reflect the needs of his material and of his narrative rather than conforming to the dictates of grammar, narrowly construed. When he writes, for example, of the Spanish which 'was beginning to speak me' (p. 114), it is in the context of a discussion of how language infiltrates our habits and forms our perspectives. This seemingly transgressive grammar - we speak a language rather than are spoken by it in English, though the passive form is common in Spanish - is in fact a way of rendering more precisely the process by which a language comes to implant itself in our minds and grow to be a (cultural) habit.

As individual languages vie with and, in certain contexts, displace one another, it is possible to reflect on their relative merits and potential limitations and to come to understand the basis on which one dominates or subjugates the other. So when Dorfman talks about 'creating a territory from which to think the phenomenon' (pp. 115-16), he is referring to the possibility of constructing a space, be it textual, emotional or ideological (see p. 220), which permits one to be both inside and outside of language. In such a space, the structures of one language are free to interrogate and influence those of the other, rather than having to remain in watertight compartments. It is this cross-fertilization (see $\mathrm{p}$. 115), to use Dorfman's term, which brings into existence a new (means of) representation.

To conclude, then: Heading South, Looking North is a text which relates the experience of living in translated worlds. It tells of Dorfman's attempts to come to terms with his bilingualism and biculturalism and to see them not as constraining but as empowering. His initial desire to anchor himself to one language and culture at the expense of the other fails to be realised for historical, political and finally personal reasons. Migration, both voluntary and enforced, has given Dorfman the possibility of crossing not only national but also cultural and linguistic borders. While as a child and adolescent he tried to secure himself to the mast of one culture and one language and saw his dual status as undermining his sense of self, as a young man he begins to understand that his identity is not predicated solely on ideas of nationhood and national heritage. Rather he begins 
to see through his writing the possibility of having a 'dialogue with language which could be deepened regardless of where that body happened to be, what contingent geography surrounded me' (p. 84). What is essential, 'the bedrock of who I am' (p. 263) cannot be equated to geographical boundaries or ring-fenced by a specific language or culture. Indeed it is access to the linguistic and cultural resources of both English and Spanish, America and Latin America which give to Dorfman the necessary resources for creating alternative worlds with alternative words. His subjectivity is not co-terminous with his experience in and of one or other language but is constituted by dialogue between them. It is in this sense that we can speak of 'translating' the self.

Fiona J. Doloughan Institute of Education University of London

\section{Note}

1. A version of this article was given at the second annual conference of the International Association for Languages and Intercultural Communication, Leeds 2001.

\section{References}

Bhabha, H. (1994) The Location of Culture (p. 172). London: Routledge.

Dorfman, A. (1998a) Heading South, Looking North (p. 269). London: Hodder \& Stoughton.

Dorfman, A. (1998b) Heading South, Looking North (p. 275). London: Hodder \& Stoughton.

Hoffman, E. (1991a) Lost in Translation (p. 242). Reading: Minerva.

Hoffman, E. (1991b) Lost in Translation (p. 211). Reading: Minerva.

Hoffman, E. (1991c) Lost in Translation (p. 274). Reading: Minerva.

Kress, G. (1995) Making Signs and Making Subjects: The English Curriculum and Social Futures (p. 24). London: Institute of Education. 